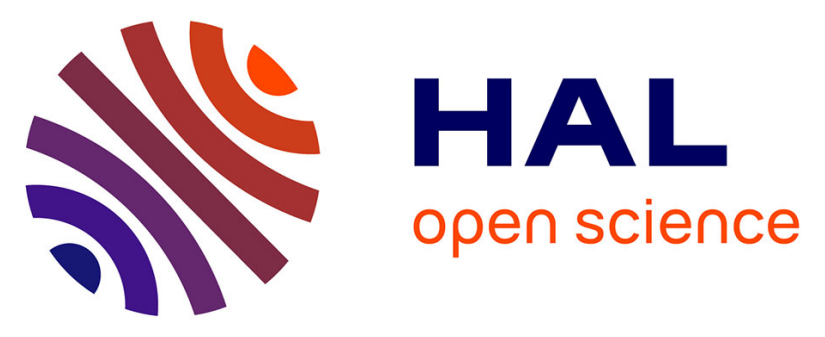

\title{
Drug-induced Stevens-Johnson syndrome and toxic epidermal necrolysis: Proportion and determinants of underreporting to pharmacovigilance
}

Guillaume Chaby, Bénédicte Lebrun-Vignes, Cynthia Haddad, Francois Hemery, Saskia Ingen-Housz-Oro, Nicolas de Prost, Pierre Wolkenstein, Olivier Chosidow, Laurence Fardet

\section{To cite this version:}

Guillaume Chaby, Bénédicte Lebrun-Vignes, Cynthia Haddad, Francois Hemery, Saskia Ingen-HouszOro, et al.. Drug-induced Stevens-Johnson syndrome and toxic epidermal necrolysis: Proportion and determinants of underreporting to pharmacovigilance. Journal of Allergy and Clinical Immunology: In Practice, 2019, 7, pp.1344 - 1346. 10.1016/j.jaip.2018.09.028 . hal-03486276

\author{
HAL Id: hal-03486276 \\ https://hal.science/hal-03486276
}

Submitted on 20 Dec 2021

HAL is a multi-disciplinary open access archive for the deposit and dissemination of scientific research documents, whether they are published or not. The documents may come from teaching and research institutions in France or abroad, or from public or private research centers.
L'archive ouverte pluridisciplinaire HAL, est destinée au dépôt et à la diffusion de documents scientifiques de niveau recherche, publiés ou non, émanant des établissements d'enseignement et de recherche français ou étrangers, des laboratoires publics ou privés.

\section{(ㄷ)(1) $\$$}

Distributed under a Creative Commons Attribution - NonCommerciall 4.0 International 


\section{Drug-induced Stevens-Johnson syndrome and toxic} 2 epidermal necrolysis: proportion and determinants of 3 underreporting to pharmacovigilance

4

5 Guillaume Chaby, MD ${ }^{1}$, Bénédicte Lebrun-Vignes, MD ${ }^{1,2}$, Cynthia Haddad, MD ${ }^{1}$, Francois 6 Hemery, $\mathrm{MD}^{3}$, Saskia Ingen-Housz-Oro, $\mathrm{MD}^{1,4}$, Nicolas de Prost, $\mathrm{MD} \mathrm{PhD}^{5}$, Pierre 7 Wolkenstein, $\mathrm{MD} \mathrm{PhD}^{1,4}$, Olivier Chosidow, $\mathrm{MD} \mathrm{PhD}^{1,4,6}$, Laurence Fardet, $\mathrm{MD} \mathrm{PhD}^{1,4}$

8

${ }^{1}$ EA 7379 EpiDermE, Université Paris Est Créteil, France

${ }^{2}$ Department of Pharmacovigilance, Hôpital Pitié-Salpétrière, AP-HP, Paris, France

${ }^{3}$ Department of Medical Informatics, Hôpital Henri Mondor, AP-HP, Créteil, France

${ }^{4}$ Department of Dermatology and Reference center for Toxic Bullous diseases, Hôpital Henri-Mondor, AP-HP,

Créteil, France

${ }^{5}$ Department of Intensive Care, Hôpital Henri-Mondor, AP-HP, Créteil, France

${ }^{6}$ INSERM, Centre d'Investigation Clinique 1430, Créteil, France

Correspondence: Guillaume Chaby

EA 7379 - department of dermatology

Hôpital Henri Mondor - Université Paris Est Créteil

51 avenue du Maréchal de Lattre de Tassigny

94000 CRETEILPhone : +33149814506

e-mail : chaby.guillaume@chu-amiens.fr

Funding: none

Conflict of interest: the authors declare no conflict of interest for this work.

Text word count: 998 


\section{Clinical Implications box}

More than two thirds of French SJS/TEN cases are not reported to the French national pharmacovigilance. This high underreporting rate is alarming because it may lead to failure to detect early an unacceptable risk associated with a drug.

\section{To the editor:}

Stevens-Johnson syndrome (SJS) and toxic epidermal necrolysis (TEN) are immunologicallymediated severe cutaneous adverse reactions (SCARs) secondary in most cases to the administration of a drug. ${ }^{1}$ Reporting to national pharmacovigilance databases is an important source of information on adverse drug reactions (ADRs). In France, healthcare professionals, including physicians and pharmacists, are legally required to report to pharmacovigilance all suspected ADRs. However, it has been estimated that only 5 to $15 \%$ of serious ADRs are reported to pharmacovigilance, even though very little accurate data is available. ${ }^{2,3}$ No data are available regarding SJS/TEN cases.

The aims of this study were to estimate the underreporting (i.e., any not reported cases) rate of SJS/TEN to pharmacovigilance and to assess determinants of underreporting.

This was a retrospective study of all observations of SJS/TEN reported to the French pharmacovigilance network from 3 national sources: RegiSCAR France (2003-2012, 20152016), Programme de Médicalisation des Systèmes d'Information -PMSI- (2008-2016) and French Epidemiological Center for the Medical Causes of Death -CépiDC- (2003-2015). The French pharmacovigilance consists of a network of 31 regional pharmacovigilance centers mandated to collect reports of ADRs that healthcare professionals are legally required to declare in France since 1995. ${ }^{4}$ ADRs are collected, documented, reviewed, and stored using a 
standardized file. For this study, the preferred terms SJS/PT(10042033) and TEN/PT(10044223) were used to identify SJS/TEN cases. RegiSCAR France is a network of dermatology departments spread over France involved in care of patients with SCARs. An employee of the registry helps physicians to include patients in the registry and reminds them to declare cases to the pharmacovigilance. All cases of drug-induced SJS/TEN collected in the registry were included. CépiDC is an administrative database collecting the medical causes of death from the anonymized death certificates. PMSI database contains administrative and medical data on hospital stays in France. Both for CépiDC and PMSI, the diagnoses are encoded using the ICD-10 classification used in France since 1998. We extracted cases of SJS/TEN using L511 and L512 codes and excluded PMSI patients with hospital stay duration $\leq 7$ days and who did not die or did not stay in an intensive care unit. We cross-checked four variables (i.e. age, gender, date of SJS/TEN, and localization of hospital stay) to identify in pharmacovigilance patients from the other databases.

Groups were compared by the Wilcoxon or Student t-test for continuous variables and the chisquare or Fisher's exact test for categorical variables. Multivariate logistic regression models were used to identify independent variables associated with underreporting. Variables associated with the outcome with a p-value $<0.20$ in univariate analyses were included in the multivariate models. Statistical analyses were performed using Stata version 14.0. The Commission Nationale de l'Informatique et des Libertés approved extraction and analyses of data from each databases

Characteristics of patients and proportions of underreporting are detailed in Table $\mathbf{1 .}$ Underreporting rates were $30.7 \%$ for RegiSCAR, $69.0 \%$ for CépiDC and $71.2 \%$ for PMSI, respectively ( $\mathrm{p}<0.001$ for the comparison of the 3 databases). Few variables were associated 
with underreporting (Table 2). Compared to reported cases from the PMSI database, the underreported cases were younger and more often male. Among the patients who died (CépiDC database), SJS/TEN overlap and TEN cases were more underreported than SJS cases. The rate of underreporting in patients recorded in RegiSCAR database significantly increased with time. Interestingly, evolution to death was not associated with reporting to pharmacovigilance.

At the national level, more than two thirds of suspected SJS/TEN cases were not reported to the pharmacovigilance system, whether or not the patients died. This high underreporting rate is alarming since SJS/TEN is probably one of the most severe and most iconic ADR. This confirms previous data evidencing that underreporting of ADRs does not concern only outpatients seen by GPs but also inpatients cared for by hospital-based physicians. ${ }^{3}$

However, underreporting was much lower for patients included in RegiSCAR. This may be explained both because someone actively reminded the physician to declare the case and/or because dermatologists with experience with SJS/TEN may be more aligned with the responsibility to report the cases.

Our study included a very large number of SJS/TEN cases, with sources of information extracted from three different national databases, each one with its own characteristics. Therefore, our findings are probably a good description of the magnitude of underreporting of severe ADRs. There are, however, some limitations, most of them being inherent to the use of administrative databases. First, there may have some misclassifications in PMSI and CépiDC databases in which diagnoses are based on codes. Since SJS and erythema multiform may be difficult to distinguish clinically and to code using ICD10 codes (code L510 "non-bullous erythema multiform" and L511 "bullous erythema multiform"), SJS is often over-diagnosed when searched for by coding in electronic healthcare databases. ${ }^{5}$ In order to limit this bias, we 
excluded from PMSI database all patients with short hospital stay if they did not die or did not

106 stay in intensive care unit. Further, it may be hypothesized that reporting was associated with

107 the culprit drug and/or the avoidability of SJS/TEN. These were likely to be different between

108 men and women and between younger and older patients. ${ }^{6}$ If this unavailable information

109 would have been included in the analyses, results regarding predictors may have been

110 different. Second, some cases of SJS/TEN not associated with a specific drug exposure could

111 have been included among PMSI and CépiDC cases, which may have introduced an

112 overestimation of underreporting. However, non-drug induced SJS/TEN account for only

$11310 \%$ of all SJS/TEN cases. ${ }^{7,8}$ Lastly, these results reflect French practices and we are unsure

114 whether they reflect practices in other countries.

115 Reporting ADRs to national pharmacovigilance databases plays a critical role in enhancing 116 drug safety in the post-marketing setting and, at the national level, may help improve 117 treatment decision making. Under-reporting may be minimized by different methods such as 118 passive (i.e., facilitating the process) or active (e.g., collaboration between 119 pharmacovigilance and medical staffs, teaching session) promotion of ADR reporting or 120 automation of the process (i.e., computer programs). ${ }^{9}$ Projects encouraging patients to proactively report ADR should also be favored. ${ }^{9}$ 


\section{References}

1. Duong TA, Valeyrie-Allanore L, Wolkenstein P, Chosidow O. Severe cutaneous adverse reactions to drugs. Lancet 2017;390:1996-2011.

2. Hazell L, Shakir SA. Under-reporting of adverse drug reactions: a systematic review. Drug Saf. 2006;29:385-96.

3. Bégaud B, Martin K, Haramburu F, Moore N. Rates of spontaneous reporting of adverse drug reactions in France. JAMA 2002;288:1588.

4.https://www.legifrance.gouv.fr/affichTexte.do?cidTexte=JORFTEXT000000531081\&categ orieLien=id (last access September 24th 2018)

5. Davis RL, Gallagher MA, Asgari MM, Eide MJ, Margolis DJ, Macy E, et al. Identification of Stevens-Johnson syndrome and toxic epidermal necrolysis in electronic health record databases. Pharmacoepidemiol Drug Saf. 2015;24:684-92

6. Chaby G, Valeyrie-Allanore L, Duong TA, Lebrun-Vignes B, Wolkenstein P, Chosidow O et al; on behalf the RegiSCAR group. Severe cutaneous adverse reactions due to inappropriate medication use. Br J Dermatol 2018 Jan 20. doi: 10.1111/bjd.16365.

7. Chaby G, Ingen-Housz-Oro S, De Prost N, Wolkenstein P, Chosidow O, Fardet L. Idiopathic Stevens-Johnson syndrome and toxic epidermal necrolysis: prevalence and patients characteristics. Submitted for publication.

8. White KD, Abe R, Ardern-Jones M, Beachkofsky T, Bouchard C, Carleton B et al. SJS/TEN 2017: Building Multidisciplinary Networks to Drive Science and Translation. J Allergy Clin Immunol Pract 2018;6:38-69.

9. Ribeiro-Vaz I, Silva AM, Costa Santos C, Cruz-Correia R. How to promote adverse drug reaction reports using information systems - a systematic review and meta-analysis. BMC Med Inform Decis Mak 2016;16:27. 
Table 1. Patients' characteristics

\begin{tabular}{lcccc}
\hline & FPV & PMSI & RegiSCAR & CépiDC \\
\hline Identified cases, No. & 1273 & 1516 & 352 & 348 \\
Number of cases not notified & - & $1080(71.2)$ & $108(30.7)$ & $240(69.0)$ \\
to the FPV, No. $(\%)$ & & & & \\
Age (years), mean \pm SD & $49.4 \pm 24.4$ & $46.4 \pm 28.5$ & $48.1 \pm 22.5$ & $69.5 \pm 19.4$ \\
Women, No. $(\%)$ & $694(54.5)$ & $763(50.3)$ & $194(55.1)$ & $188(54.0)$ \\
Diagnosis, No. $(\%)$ & & & & \\
$\quad$ SJS & $730(57.3)$ & $824(54.4)$ & $142(40.3)$ & $38(10.9)$ \\
$\quad$ SJS/TEN overlap and TEN & $543(42.7)$ & $692(45.6)$ & $210(59.7)$ & $310(89.1)$ \\
Evolution to death, No. $(\%)$ & $191(15.0)$ & $190(12.5)$ & $48(13.6)$ & $348(100)$ \\
\hline
\end{tabular}

FPV : French PharmacoVigilance

PMSI : Programme de Médicalisation des Systèmes d'Information

CépiDC: French Epidemiological Center for the Medical Causes of death

SD: standard deviation

SJS: Stevens-Johnson syndrome

164 TEN: toxic epidermal necrolysis 
Table 2. Factors associated with underreporting to pharmacovigilance

\begin{tabular}{|c|c|c|c|c|c|}
\hline & \multicolumn{3}{|c|}{ Univariate analyses } & \multicolumn{2}{|c|}{ Multivariate analyses } \\
\hline & Reported cases & Not reported cases & p-value & OR $[95 \% \mathrm{CI}]$ & p- value \\
\hline PMSI, No.(\%) & $436(28.8)$ & $1080(71.2)$ & & & \\
\hline Age (years), mean (SD) & $50.2(25.9)$ & $44.9(29.4)$ & 0.001 & $0.95[0.91-0.99]^{\mathrm{a}}$ & 0.02 \\
\hline Women, No.(\%) & $242(55.5)$ & $521(48.2)$ & 0.01 & $0.78[0.62-0.97]$ & 0.03 \\
\hline Diagnosis, No. (\%) & & & 0.21 & - & - \\
\hline SJS & $226(51.8)$ & $598(55.4)$ & & & \\
\hline SJS/TEN overlap and TEN & $210(48.2)$ & $482(44.6)$ & & & \\
\hline Evolution to death, No. (\%) & $67(15.4)$ & $123(11.4)$ & 0.03 & $0.79[0.57-1.11]$ & 0.17 \\
\hline Year of notification, median [IQR] & 2012 [2010-2014] & 2012 [2010-2014] & 0.99 & - & - \\
\hline RegiSCAR, No.(\%) & $244(69.3)$ & $108(30.7)$ & & & \\
\hline Age (years), mean (SD) & $47.0(22.7)$ & $50.5(21.9)$ & 0.17 & $1.07[0.97-1.19]^{\mathrm{a}}$ & 0.20 \\
\hline Women, No.(\%) & $132(54.1)$ & $62(57.4)$ & 0.56 & - & - \\
\hline Diagnosis, No.(\%) & & & 0.91 & - & - \\
\hline SJS & $98(40.1)$ & $44(40.7)$ & & & \\
\hline SJS/TEN overlap and TEN & $146(59.8)$ & $64(59.2)$ & & & \\
\hline Evolution to death, No. \% & $34(13.9)$ & $14(12.9)$ & 0.80 & - & - \\
\hline Year of notification, median [IQR] & 2007 [2004-2010] & 2009 [2006-2011] & 0.0001 & $1.12[1.06-1.20]^{\mathrm{b}}$ & $<0.0001$ \\
\hline CépiDC, No.(\%) & $108(31.0)$ & $240(69.0)$ & & & \\
\hline Age (years), mean (SD) & $68.1(18.0)$ & $70.1(20.0)$ & 0.38 & - & - \\
\hline Women, No.(\%) & $55(50.9)$ & $133(55.4)$ & 0.44 & - & - \\
\hline \multicolumn{6}{|l|}{ Diagnosis, No.(\%) } \\
\hline SJS & $19(17.6)$ & $19(7.9)$ & 0.007 & $2.48[1.26-4.91]$ & 0.009 \\
\hline SJS/TEN overlap and TEN & $89(82.4)$ & $221(92.1)$ & & & \\
\hline Year of notification, median [IQR] & 2008 [2005-2012] & 2009 [2006-2012] & 0.59 & - & - \\
\hline
\end{tabular}

